\title{
Characterization of wheat Bell1-type homeobox genes in floral organs of alloplasmic lines with Aegilops crassa cytoplasm
}

\author{
Kota Mizumoto ${ }^{1}$, Hitoshi Hatano ${ }^{1}$, Chizuru Hirabayashi ${ }^{2}$, Koji Murai $^{2}$, Shigeo Takumi ${ }^{*}$
}

\begin{abstract}
Background: Alloplasmic wheat lines with Aegilops crassa cytoplasm often show homeotic conversion of stamens into pistils under long-day conditions. In the pistillody-exhibiting florets, an ectopic ovule is formed within the transformed stamens, and female sterility is also observed because of abnormal integument development.

Results: In this study, four wheat Bell1-like homeobox (BLH) genes were isolated and named WBLH1 to WBLH4. WBLH1/WBLH3/WBLH4 expression was observed in the basal boundary region of the ovary in both normal pistils and transformed stamens. WBLH2 was also strongly expressed in integuments not only of normal ovules in pistils but also of the ectopic ovules in transformed stamens, and the WBLH2 expression pattern in the sterile pistils seemed to be identical to that in normal ovules of fertile pistils. In addition, WBLH1 and WBLH3 showed interactions with the three wheat KNOX proteins through the BEL domain. WBLH2, however, formed a complex with wheat KNOTTED1 and ROUGH SHEATH1 orthologs through SKY and BEL domains, but not with a wheat LIGULELESS4 ortholog.

Conclusions: Expression of the four WBLH genes is evident in reproductive organs including pistils and transformed stamens and is independent from female sterility in alloplasmic wheat lines with Ae. crassa cytoplasm. KNOX-BLH interaction was conserved among various plant species, indicating the significance of KNOX-BLH complex formation in wheat developmental processes. The functional features of WBLH2 are likely to be distinct from other $B L H$ gene functions in wheat development.
\end{abstract}

\section{Background}

Alien cytoplasm largely alters gene expression profiles, affecting growth and organogenesis. Nuclear-cytoplasm incompatibility results in abnormal growth phenotypes in higher plants [1,2]. Recurrent backcrossing has been commonly used for production of nuclear-cytoplasmic substitution plants called alloplasmic lines, in which the cytoplasmic genomes are replaced by ones from a related species [3]. Cytoplasmic male sterility is a major phenomenon among the abnormal phenotypes of the alloplasmic lines $[1,4]$. In many cases of cytoplasmic male sterility, nuclear-cytoplasm incompatibility induces abortion of pollen. Homeotic transformation of stamens into pistil-like structures is sometimes observed in

\footnotetext{
* Correspondence: takumi@kobe-u.ac.jp

${ }^{1}$ Graduate School of Agricultural Science, Kobe University, Nada-ku, Kobe 657-8501, Japan

Full list of author information is available at the end of the article
}

alloplasmic lines of carrot, Brassica napus, tobacco and wheat [5-9], a phenomenon called pistillody.

Cytoplasm of a wild wheat relative, Aegilops crassa, homeotically affects floral organ development and induces pistillody in some alloplasmic common wheat lines lacking fertility restorer genes against Ae. crassa cytoplasm (Figure 1) [10,11]. The mitochondrial orf260 gene in the Ae. crassa cytoplasm might be associated with induction of the floral homeotic change [12]. An alloplasmic line of the wheat cultivar Norin 26 (N26) with Ae. crassa cytoplasm [(cr)-N26] exhibits male sterility under long-day conditions (> $15 \mathrm{~h}$ light period) due to pistillody (Figure 1E, F), a phenomenon termed photoperiod-sensitive cytoplasmic male sterility [10]. However, an alloplasmic line of the wheat cultivar Chinese Spring (CS) does not because of a fertility restorer gene Rfd1, located on the long arm of chromosome 7B (Figure 1A) [13]. An alloplasmic line of CS (ditelosomic

\section{Biomed Central}


(A)

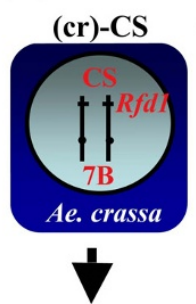

normal

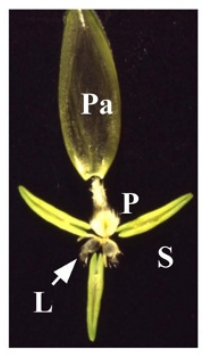

(B)
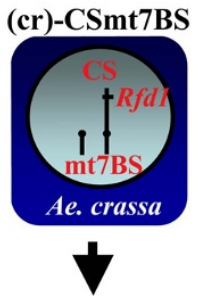

partial pistillody

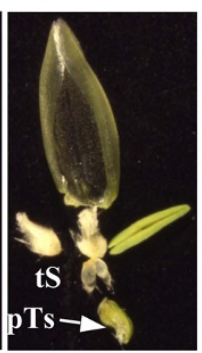

(C)
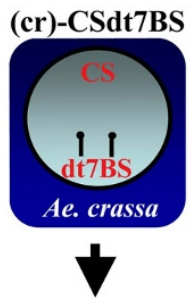

(D)

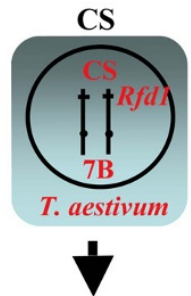

pistillody female sterile

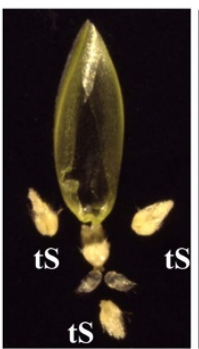

(E)
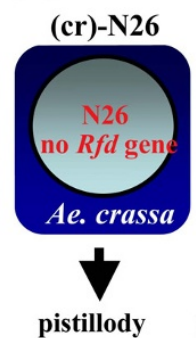

(long day condition)

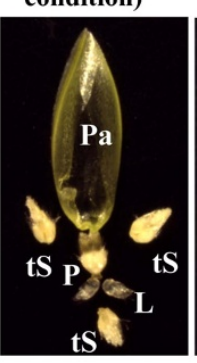

(F)

(cr)-N26
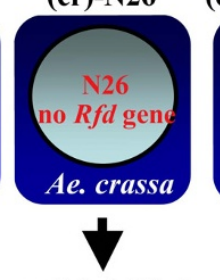

partial pistillody (short day condition)

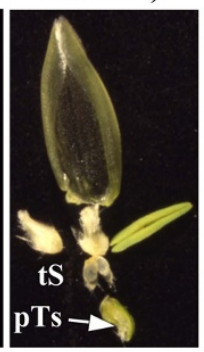

(G)

(H)

(cr)-N26 mutant (cr)-N61
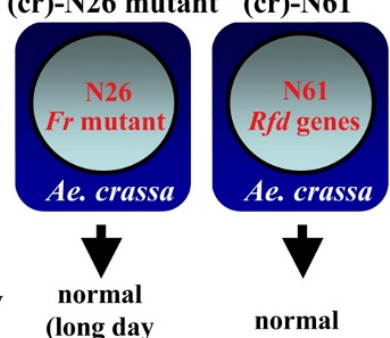

condition)

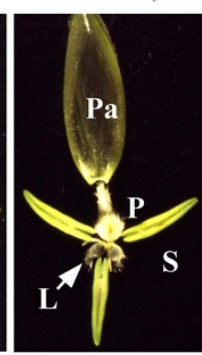

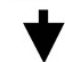

normal

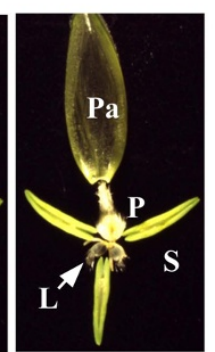

Figure 1 Photoperiod-sensitive cytoplasmic male sterility in alloplasmic wheat with Ae. crassa cytoplasm. Genetic characteristics of nuclear and cytoplasmic types and floral organ morphology without the lemma in the alloplasmic lines are schematically represented. (A) (cr)-CS has normal stamens because of the fertility restorer gene Rfd1 against the Ae. crassa cytoplasm on the long arm of chromosome 7B. (B) (Cr)-CS monotelodisomic 7BS, which has Rfd1 in a hemizygous state, shows partial pistillody (arrow) and reduced female fertility. (C) (Cr)-CS ditelosomic 7BS, which lacks both of the long arms pair of chromosome 7B and therefore lacks Rfd1, shows complete pistillody and female sterility, independent of day length. Floral organ morphology of CS ditelosomic 7BS was indistinguishable from that of CS. (D) Euplasmic CS. (E) (Cr)-N26 shows homeotic transformation of stamens into pistils (pistillody) only under long-day conditions. (F) (cr)-N26 occasionally shows partial pistillody (arrow) and reduced female fertility under short-day conditions. (G) An EMS-induced mutant of (cr)-N26 shows normal floral phenotype [36]. This mutant fails to measure day length. (H) (cr)-N61, which contains multiple loci for Rfd genes, shows normal floral phenotype. Pa, palea; P, pistil; S, stamen; L, lodicule; PTs, partially transformed stamen; Ts, transformed stamen.

7BS) with Ae. crassa cytoplasm [(cr)-CSdt7BS] lacking both long arms of the homologous chromosome 7B shows pistillody unrelated to day length (Figure $1 \mathrm{C}$ ), but CS ditelosomic 7BS with the intrinsic cytoplasm (CSdt7BS) forms normal stamens (Figure 1D) [6].

The Ae. crassa cytoplasm alters expression patterns of wheat class B MADS-box genes at the floral meristem of (cr)-CSdt7BS [6]. Primordia of the pistil-like stamens lack expression of wheat APETALA3 (AP3) and PISTILLATA (PI) orthologs such as WAP3, WPI-1 and WPI-2 [14], whereas two wheat class C MADS-box genes, wheat AGAMOUS paralogs (WAG-1 and WAG-2), are ectopically expressed at the pistil-like stamens $[15,16]$. Despite initiation of ovule formation in these transformed stamens, ectopic ovules incompletely develop, and the transformed stamens are sterile. In addition, pistils are also sterile in the (cr)-CSdt7BS alloplasmic line, and female sterility is due to abnormal ovule development [6]. Both the ovules and ectopic ovules fail to form an inner epidermis and integuments in the chalaza region. This incomplete development of the ovules strongly suggests alteration of gene expression patterns essential to normal ovule formation in pistils and pistillike stamens of the (cr)-CSdt7BS alloplasmic line. However, there is little information about gene expression associated with wheat ovule development.

Following determination of carpel identity via $A G A$ MOUS ( $A G$ ), a class C MADS-box gene acting to specify stamen and carpel development in Arabidopsis [17], ovule primordia are initiated within pistils. The initiation of ovule primordium formation is caused by expression of class D MADS-box genes such as Arabidopsis SEEDSTICK (STK) and petunia floral binding protein 7 (FBP7) and FBP11 [18-20]. ARABIDOPSIS BSISTER $(A B S)$ and $F B P 24$ from petunia are members of the $B_{\text {sis- }}$ ter subfamily, and are necessary to determine the identity of the endothelial layer within the inner integument of the ovule $[21,22]$. Our previous study using wheat alloplasmic lines with Ae. crassa cytoplasm demonstrated that alteration of class B and C MADS-box genes was 
connected with continuous transcript accumulation of class D and $\mathrm{B}_{\text {sister }}$ MADS-box genes, WSTK and WBsis, respectively, in primordia of ectopic ovules within the pistil-like stamens [23]. Moreover, the WBsis transcript is not restricted to the endothelium and appears at the nucellus in ectopic ovules in (cr)-CSdt7BS. Arabidopsis AINTEGUMENTA (ANT) plays an important role in ovule development along the proximal-distal axis [24]. ant mutants fail to both initiate and elongate the integument $[25,26]$. The aberrant ovule formation is at least partly associated with the weak expression of a wheat ANT homolog WANT-1 around ovule primordia in (cr)CSdt7BS [16]. Therefore, alteration of gene expression after initiation of ovule primordia results in abnormal ovule development in alloplasmic wheat with Ae. crassa cytoplasm.

Arabidopsis homeodomain protein BELL1 (BEL1) is also required for ovule morphogenesis [27], suggesting that wheat BEL1 homologs may be associated with ovule development. BEL1 acts to specify integument identity by controlling $A G$ activity [28]. BEL1 encodes a TALE homeodomain transcription factor distantly related to the PBX family [27]. Plant BEL1-like homeobox $(B L H)$ genes form a small gene family functioning in various developmental aspects such as seed shattering in rice [29] and leaf shape establishment in Arabidopsis [30]. For many of the $B L H$ functions, molecular interaction with KNOTTED1-type homeodomain (KNOX) proteins is required. Barley JuBel1 and JuBel2 were originally isolated as interaction partners of the KNOX protein BKN3 [31]. Arabidopsis BELLRINGER (syn. $P E N N Y W I S E$ ) functions with $K N O X$ genes in early patterning of inflorescence architecture and in maintenance of the inflorescence meristem [32,33]. The BEL domain of $\mathrm{BLH}$ directly interacts with the MEINOX domain of KNOX, and the interaction is evolutionarily conserved between animals and plants [34,35].

To elucidate molecular mechanisms of the abnormal ovule development in alloplasmic wheat with Ae. crassa cytoplasm, we first isolated wheat cDNA clones for the $B L H$ homologs, and then studied their differential expression patterns and interaction with wheat KNOX proteins. Association of the $B L H$ homologs with pistillody and female sterility in (cr)-CSdt7BS is discussed based on the results.

\section{Methods}

\section{Plant materials}

Three common wheat (Triticum aestivum L., genome constitution AABBDD) cultivars, Chinese Spring (CS), Norin26 (N26) and Norin61 (N61), and a ditelosomic 7BS line of CS (CSdt7BS) were used in this study. Euplasmic lines of each with their intrinsic cytoplasm develop normal fertile reproductive organs. Alloplasmic lines with the cytoplasm of a wild relative, Aegilops crassa, used in the study were respectively abbreviated as (cr)-CS, (cr)-N26, (cr)-N61 and (cr)-CSdt7BS. The (cr)-N26 shows pistillody when grown under long-day conditions (Figure 1E), and exhibits partial pistillody under short-day conditions, implying that N26 might contain a fertility restorer $(R f)$ gene functioning under short-day conditions (Figure 1F) [10]. Both (cr)-CS and (cr)-N61 show normal male fertility because of their possession of $R f$ gene(s) against the Ae. crassa cytoplasm in their nuclear genome (Figure 1A, H) [11]. CS has a single dominant $R f$ gene, $R f d 1$, on the long arm of chromosome 7B (7BL) and N61 has multiple $R f$ genes. A CS monotelodisomic line of chromosome 7BS with the $A e$. crassa cytoplasm [(cr)-CSmt7BS] is hemizygous for $R f d 1$ and partially fertile (Figure 1B). (cr)-CSdt7BS, which was generated from a cross of (cr)-CSmt7BS with CSdt7BS, shows not only pistillody but also female sterility, independently of day length (Figure 1C) [6]. An Fr mutant of (cr)-N26 obtained after EMS mutagenesis of (cr)-N26 shows no pistillody even under long-day conditions (Figure 1G) [36], and was used in the expression analysis.

Three accessions of ancestral diploid species, Triticum urartu (AA), Aegilops speltoides (SS) and Aegilops tauschii (DD), and the tetraploid wheat (Triticum durum, $\mathrm{AABB})$ cultivar Langdon were used in DNA gel blot analysis. A nulli-tetrasomic series of CS produced by Sears [37] was used for chromosome assignment of the isolated wheat cDNAs. Each line of the nulli-tetrasomic series lacks a given pair of homoeologous $\mathrm{A}, \mathrm{B}$ or $\mathrm{D}$ genome chromosomes (the nullisomic condition) that have been replaced by the corresponding homoeologous chromosome pair (the tetrasomic condition).

\section{Cloning and sequencing of wheat BELL1 homologs}

Degenerate primers, 5'-CGA(A/G)CACTTCCT(A/G/C/T) CACCCGT-3' and 5'-AC(C/G)C(G/T)(C/G/T)GCGTTGAT (A/G)AACCA-3', were designed and used for amplification of the BEL domain regions in RNA from pistils of CS and (cr)-CSdt7BS. The reverse transcription (RT)-PCR products were cloned into the pGEM-T Easy vector (Promega, Madison, WI, USA) and nucleotide sequences were determined by an automated fluorescent DyeDeoxy terminator cycle sequencing system using an ABI PRISM 310 genetic analyzer (Applied Biosystems, Foster City, CA, USA). Nucleotide sequences of the isolated cDNA fragments were analyzed by DNASIS software (Hitachi, Tokyo, Japan) and the sequence was searched for homology using the BLAST algorithm [38].

The cDNA fragments were used to search wheat expression sequence tag (EST) clones, and the identified EST clone TaLr1107F03R contained the complete open reading frame (ORF). To identify other BLH cDNA clones, first-strand cDNA was synthesized using total RNA from pistils of CS and (cr)-CSdt7BS, and 5' and 3' 
RACE-PCR was performed with a SMART-RACE PCR kit (BD Bioscience Clontech, Tokyo, Japan) according to the manufacturer's procedure. Gene-specific primers for RACE-PCR were designed based on the nucleotide sequences of the degenerate primer-amplified RT-PCR products. For 5' and 3' RACE-PCR, the following primers were respectively used: 5'-TCCTCGCCGCCAGCATGTCCTTCTCGT-3' and 5'-AAGTCCGTCGC CGTGCTCAAAGCCTGG-3' for WBLH2, 5'-TTTGAGACCTGATTCCTCGTTAAGCCTG-3' and 5'-CAGCAAGGTGGCCGCCGGGAAAGACAG-3' for WBLH3, and 5'-GGCCAGCATTTGCTTGTCGCCATCGGTA-3' and 5'-GCGCAACACCAGCAAGATGCCGGTCAA-3' for WBLH4. A cDNA fragment containing the complete ORF was amplified with the following primer sets: 5'CCGACGACGACGATGATGAC-3' and 5'-CCTTAG CCCCCCCAAGAATA-3' for WBLH1, 5'-CGGTGCT TTCTCTCTCCATG-3' and 5'-TTCCTAGCCGACGACGTCTT-3' for WBLH2, and 5'-CCTCCCTCT CTCTCCCCCTT-3' and 5'-TGATCCCAGCAATGGAGCAA-3' for WBLH3. The nucleotide sequences of the isolated cDNA clones were analyzed as mentioned above, and a phylogenetic tree was constructed by GENETYX-MAC version 12.00 software (Whitehead Institute for Biomedical Research, Cambridge MA) based on Nei's genetic distance. The phylogenetic tree was constructed according to the unweighted pair group method with arithmetic mean (UPGMA) method [39].

\section{Southern blot and RT-PCR analyses}

For genomic Southern blot analysis, total DNA extracted from CS, Langdon and diploid wheat was digested with the restriction enzyme HindIII. Total DNA extracted from the nulli-tetrasomics was also digested with HindIII, DraI and BamHI. The digested DNA was fractionated by electrophoresis through a $0.8 \%$ agarose gel, transferred to Hybond $\mathrm{N}^{+}$nylon membrane (GE Healthcare, Piscataway, NJ, USA) and hybridized with ${ }^{32}$ P-labeled partial $B L H$ cDNA fragments as a probe (Figure 2). Probe labeling, hybridization, washing and autoradiography were performed according to Takumi et al. [40].

Total RNA was extracted by guanidine thiocyanate from various tissues at the vegetative and reproductive phases in the euplasmic and alloplasmic wheat lines. Accumulation of the four $B L H$ and three KNOX transcripts was detected by RT-PCR amplification as previously reported [41]. RT-PCR was conducted with the following gene-specific primer sets: 5'-TCAACCGACAGCAGCAGCAG-3' and 5'-CCGAACCCCATCACCGAGTC-3' for WBLH1, 5'-GTGCCCAGTCTTCCTCG GTC-3' and 5'-TCCATCCACCTCCCGCCGTC-3' for WBLH2, 5'-CGCTGTCCTCGTCCTCCTCG-3' and 5'GGAGAGCGATGGAGGCAAAG-3' for $W B L H 3$, and

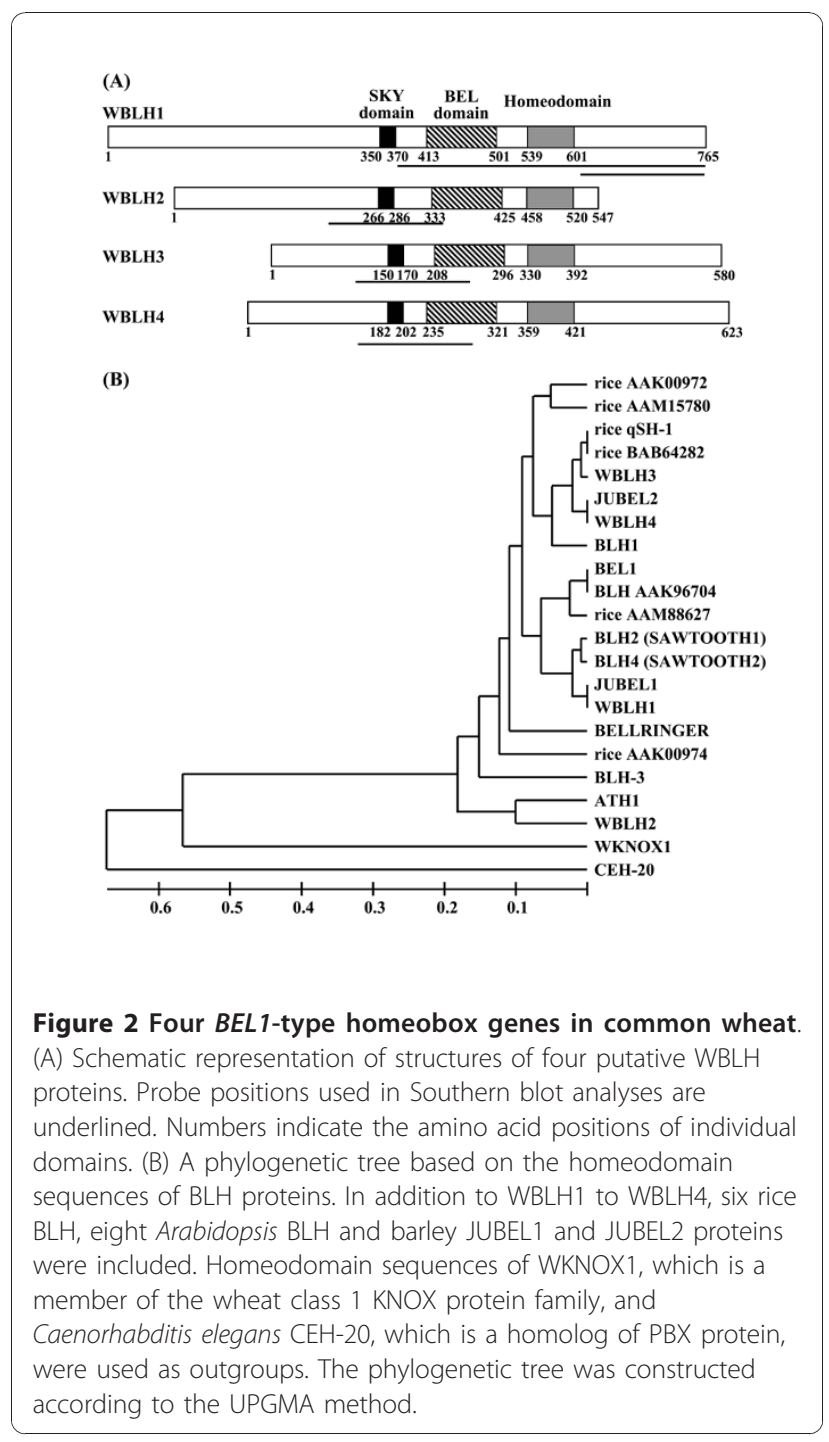

5'-CCCTCTCCTCCGCCTCGTCC-3' and 5'-CGGGG CGGCGTTGCTGAACC-3' for WBLH4. Primers for amplification of Wknox1, WRS1 and WLG4 (AB465042) transcripts are described in our previous studies [42-44]. The ubiquitin ( $U b i)$ and actin $(A c t)$ genes were used as internal controls $[41,45]$. The PCR-amplified products were separated by electrophoresis through a $1.5 \%$ agarose gel and stained with ethidium bromide. RT-PCR analysis was performed at the exponential range of amplification, and the entire experiment was conducted twice. Two technical replicates were performed for each biological replicate.

Quantitative RT-PCR was performed using a TaKaRa Thermal Cycler Dice Real Time System (TaKaRa Bio, Ohtsu, Japan) and gene-specific primer sets. As an endogenous control, the wheat Act gene was used. The rate of amplification was monitored using THUNDERBIRD SYBR pPCR Mix (Toyobo, Osaka, Japan) according to 
the manufacturer's protocol. Results were obtained as 2 $\Delta^{\mathrm{Ct}}$ values, where $\mathrm{Ct}$ is the number of PCR cycles required to reach the log phase of amplification for the examined genes minus the same measure for Act, and were represented as values relative to the transcript levels in pistils of CS, N61 or CSdt7BS.

\section{mRNA in situ hybridization}

Pistils and young spikes at the stage of floral organ development in the lines CSdt7BS and $(\mathrm{cr})$-CSdt7BS were fixed in $3.7 \% p$-formaldehyde, $5 \%$ acetic acid at $4^{\circ} \mathrm{C}$ overnight. The fixed tissues were embedded in Paraplast medium (Oxford Labware, St. Louis, MO, USA) after dehydration with ethanol and infiltration with xylene. The embedded samples were sliced into $8-\mu \mathrm{m}$ sections and dried overnight onto slides coated with VECTABOND Reagent (Vector Laboratories, Burlingame, CA, USA). Tissue sections were deparaffinized with xylene and hydrated through an ethanol series, then dehydrated through an ethanol series after treatment with proteinase $\mathrm{K}$ and triethanolamine. Hybridization of the four $B L H$ mRNAs with digoxigenin-labeled probe produced from the coding regions was performed overnight at $52^{\circ} \mathrm{C}$. The RNA probes were directly synthesized with $\mathrm{T} 3$ and $\mathrm{T} 7$ RNA polymerase (Toyobo) from the isolated cDNA clone. After hybridization, the sections were washed and treated with RNase. Immunological detection of the hybridized probe was according to Morimoto et al.[42].

\section{Yeast two-hybrid assay}

A HybriZAP-2.1 two-hybrid undigested vector kit (Stratagene, La Jolla, CA, USA) was used to study proteinprotein interaction between $\mathrm{BLH}$ and KNOX. The entire ORF sequences of wheat $B L H$ and $K N O X$ cDNA fragments were amplified with the following primer sets containing either an EcoRI, BamHI, SalI or XbaI linker: 5'-CCGAATTCATGGGAATAGCGGCGCCACC-3' and 5'-CCGTCGACTCAACAACCATTGTAGTCTC-3' for WBLH1, 5'-GGGGATCCATGTCTAGCAATCCATC CTA-3' and 5'-GGTCTAGATTCCTAGCCGACGACGT CTT-3' for WBLH2, 5'-GGGGATCCGCCGCCGCCATGTCATCGG-3' and 5'-GGGGATCCGTCGACGATCACCCAACGAGTCAT-3' for WBLH3, 5'CCGAATTCATGGAGGAGATCGGCCACCA-3' and 5'-CCCCCGGGCTAGCCGAACCTGTAGAGCC-3' for Wknox1, 5'-GGGAATTCATGGAGAAGTTCCCTAAT3' and 5'-GGGTCGACTGGAGAAAGGGAGAGAGG-3' for WRS1, and 5'-GGGAATTCATGGAGGATCTGTACAGCA-3' and 5'-GGGTCGACAGCAATCATCCATCCATCT-3' for WLG4. The PCR products were digested with EcoRI and SalI and cloned into the EcoRI/SalI sites of pAD-GAL4-2.1 and pBD-GAL4 Cam vectors, resulting in pAD-WBLH1, pAD-WBLH2, pAD-WBLH3, pBD-WKNOX1, pBD-WRS1, pBD-WLG4 and pBD-
WBLH1. Deletion derivatives of pAD-WBLH1, pAD-WBLH2 and pBD-WBLH1 were generated using internal restriction enzyme recognition sites and internal primers with the linker sequence. pAD-WT and pBDWT, containing the wild-type fragment $\mathrm{C}$ of lambda $\mathrm{CI}$, were used as controls according to the manufacturer's protocol (Stratagene). These pAD and pBD constructs were introduced into yeast strain YRG-2 (Stratagene). The interaction was assessed on SD medium (Q-BIOgene, Irvine, CA, USA) without leucine (Leu), tryptophan (Trp) or histidine (His) and containing $3 \mathrm{mM}$ 3-amino-1,2,4-triazole.

\section{Results}

\section{Cloning of wheat Bell1-like homeobox genes}

The CS line ditelosomic 7BS lacking $R f d 1$ with normal cytoplasm (CSdt7BS) forms normal stamens, whereas the alloplasmic line of CSdt7BS with Ae. crassa cytoplasm ((cr)-CSdt7BS) showed pistillody in all florets (Figure 1). To identify wheat $B L H$ homologs associated with pistillody, we designed degenerate primers based on the nucleotide sequences of rice and barley $B L H$ homologs, and amplified the 108-bp regions encoding the conserved BELL1-type homeodomains using total RNA from pistils of CS and (cr)-CSdt7BS. In total, 63 of the RT-PCR products were sequenced and classified into seven groups based on their nucleotide sequences (Additional file 1), indicating that at least seven members of the $B L H$ gene family were identified in the wheat genome. Four of the identified $B L H$ members, groups 1, 2, 3 and 7, appeared favored by either CS or (cr)-CSdt7BS.

In the wheat EST database of the Cereal Research Centre, Agriculture and Agri-Food Canada, one EST clone showed high homology to barley JuBel1 [31], and the cDNA clone TaLr1107F03R contained an entire ORF. The wheat JuBel1 homolog corresponding to the group 3 RT-PCR products was named WBLH1. Two additional cDNA sequences for $W B L H 1$ were isolated from CS. The three WBLH1 cDNAs contained single ORFs encoding 767, 765 and 771 amino acid residues, and were respectively designated WBLH1-1, WBLH1-2, and WBLH1-3. To isolate full-length cDNA clones for the group 1, 2 and 7 RT-PCR products, 5'- and 3'RACE-PCR were conducted with gene-specific primers designed for the homeobox regions. Based on the nucleotide sequences of the RACE-PCR products, three cDNA-specific primer sets were designed, and the cDNA clones identified were named WBLH2, WBLH3 and WBLH4. A WBLH2 cDNA clone encoding 547 amino acid residues was obtained, and the cDNA sequence included an 18-bp deletion in the ORF compared with the RACE-PCR product. The WBLH3 and WBLH4 cDNA clones contained an entire ORF 
encoding 580 and 623 amino acids, respectively. The isolated cDNA sequences were deposited in the DDBJ database under the accession numbers AB546641AB546647.

Putative amino acid sequences of the four wheat BLH proteins contained three conserved domains, SKY, BEL and homeodomains (Figure 2A). Based on the homeodomain sequences of four WBLH and related proteins, a phylogenetic tree was constructed (Figure 2B). The amino acid sequence of WBLH1-1 showed the highest similarity (90.2\% identity) to that of barley JuBEL1, and JuBEL2 was closely related (78.7\% identity) to WBLH4. WBLH3 showed high similarity to rice qSH1, a major quantitative trait locus controlling seed shattering through formation of an abscission layer [29]. The homeodomain of WBLH2 was highly similar to that of Arabidopsis light-induced ATH1 [46] and distantly divergent from other BEL1-related proteins. In all three conserved domains, WBLH1 showed the highest similarity to Arabidopsis BEL1 of the four WBLH proteins. Among these WBLH proteins, homeodomain sequences were highly conserved, while the SKY and BEL domains were relatively more diverged (Additional file 2). In particular, the SKY and BEL domains of WBLH2 were distinct from those of the other three WBLH proteins.

To study the copy number of WBLH1 in the wheat genome, Southern blots were analyzed using total DNA isolated from diploid, tetraploid and hexaploid wheat. Southern blots using the shorter cDNA fragment as a probe (Figure 2A) showed low copy numbers of WBLH1 in tetraploid and hexaploid wheat genomes, and a single major and a few minor bands for WBLH1 in the $\mathrm{A}, \mathrm{S}$ and $\mathrm{D}$ diploid genomes (Additional file 3 ). To assign the WBLH1 homologous loci to wheat chromosomes, aneuploid analysis was performed using a series of nullitetrasomic lines. Southern blots using the longer cDNA fragment as a probe (Figure 2A) showed that WBLH1homologous bands could be assigned to chromosomes $2 \mathrm{~B}, 4 \mathrm{~A}, 4 \mathrm{D}, 5 \mathrm{~A}, 5 \mathrm{~B}$ and $5 \mathrm{D}$ (Additional file 3), meaning that the three isolated WBLH1 cDNAs were not necessarily homoeologous. Two major bands of WBLH2 were observed in the A, S and D diploid genomes (data not shown), and the WBLH2-specific bands were absent only in the nulli-tetrasomic lines of homoeologous group 7 chromosomes and chromosomes $1 \mathrm{~A}, 2 \mathrm{~A}$ and 2D (Additional file 3). WBLH2 and its homologous loci were assigned to the six chromosomes in common wheat. Similarly, a single major band for $W B L H 3$ and WBLH4 was detected in the $\mathrm{A}, \mathrm{S}$ and $\mathrm{D}$ diploid genomes (data not shown). The WBLH3- and WBLH4specific bands were absent in the nulli-tetrasomic lines of homoeologous group 1 and 3 chromosomes, respectively (Additional file 3). These Southern bots indicated that WBLH3 and WBLH4 respectively represented three homoeologous loci of group 1 and 3 chromosomes in common wheat.

\section{Expression patterns of the four WBLH genes revealed by RT-PCR analyses}

To study expression patterns of the four WBLH genes in wheat, RT-PCR analysis was conducting using total RNA from various tissues of CS. Single bands were clearly visualized for the four $W B L H$ genes, although the gene-specific primers did not distinguish the three $A, B$, and $\mathrm{D}$ homoeoalleles of the target genes. The four wheat $B L H$ genes showed tissue-specific expression patterns (Figure 3). WBLH1 transcripts accumulated predominantly in floral organs than in vegetative organs, suggesting that these genes play important roles in wheat reproductive organ development. WBLH2 transcripts were detected in shoot and inflorescence meristem-containing tissues, and in floral organs. WBLH3 expression was observed in most tissues examined, and the expression pattern of $\mathrm{WBLH} 4$ closely resembled that of $\mathrm{WBLH}$.

Next, to compare expression patterns of the four WBLH genes in wheat florets, semi-quantitative and quantitative RT-PCR analyses were conducted using total RNA isolated from floral organs of various alloplasmic wheat lines with Ae. crassa cytoplasm. WBLH1

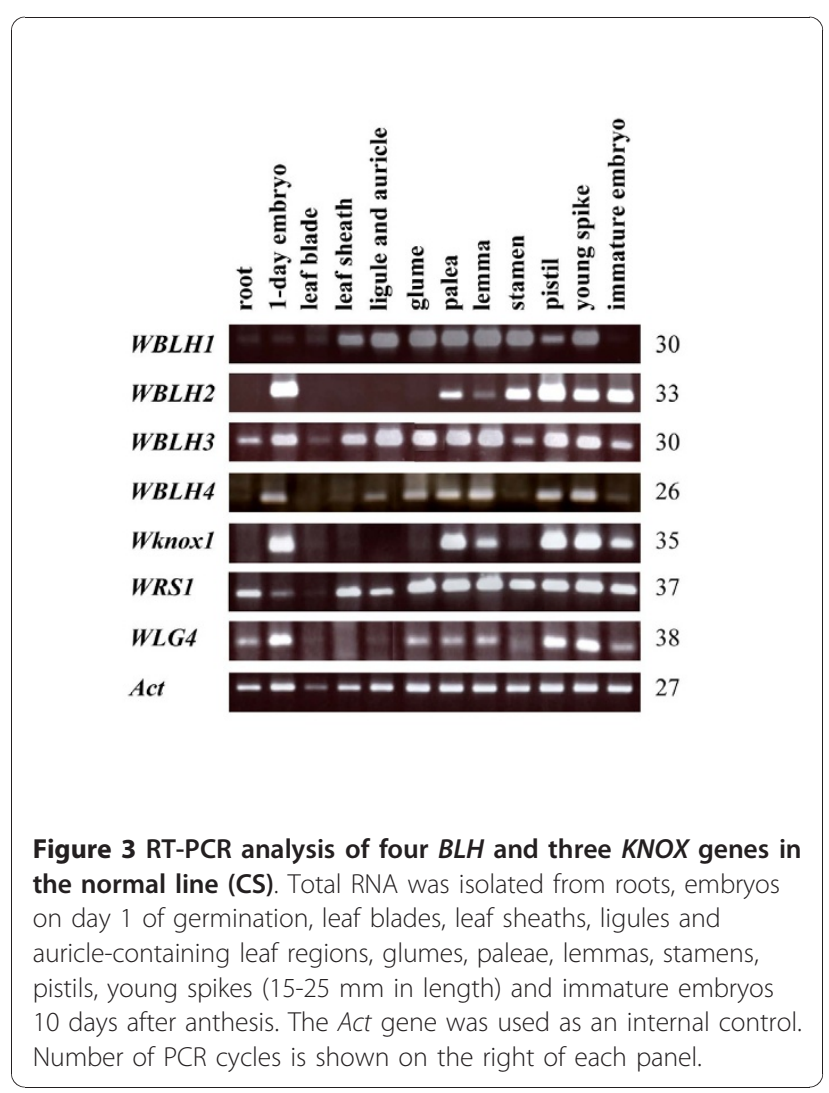


transcripts were more abundantly accumulated in stamens than in pistils and lodicules of CS, and were observed at a low level in leaves of CS seedlings (Figure 4). Similarly, abundant accumulation of WBLH1 transcripts was observed in partially transformed stamens of (cr)-CSmt7BS, but no significant difference in the WBLH1 transcript level was observed between stamens of (cr)-CS and the partially transformed stamens of (cr)CSmt7BS (Figure 5). In transformed stamens of (cr)CSdt7BS, the transcript level was similar to that in the pistils of both euplasmic and alloplasmic CS lines. To confirm abundant expression in stamens, WBLH1 expression was also analyzed using the other series of euplasmic and alloplasmic wheat lines. The WBLH1 transcripts similarly accumulated in stamens of all the lines examined (Figure 4). In partially transformed stamens of (cr)-N26, the WBLH1 transcript level was significantly reduced compared with euplasmic N26 (Figure 5).

Abundant accumulation of WBLH2 transcripts was observed in pistils and lodicules, with no transcript detected in leaves and roots of CS (Figure 4). The abundant expression of WBLH2 in pistils was also observed in the other euplasmic and alloplasmic lines. The WBLH2 transcript levels in transformed stamens of (cr)CSdt7BS and partially transformed stamens of (cr)CSmt7BS and (cr)-N26 were significantly reduced compared with those in pistils, whereas transformed stamens of (cr)-CSdt7BS had an increased WBLH2 transcript level compared with normal stamens of CSdt7BS (Figure 5). The WBLH2 transcripts in the partially transformed stamens of (cr)-CSmt7BS and (cr)-N26 accumulated at lower levels than those of fully transformed stamens.

WBLH3 and WBLH4 transcripts more abundantly accumulated in pistils and lodicules compared with stamens of CS (Figure 4). WBLH3 expression was also detected in leaves and roots. WBLH4 transcript levels were more abundant in the lodicules than in the pistils. In pistils of the other euplasmic and alloplasmic lines, predominant expression of $W B L H 3$ and $W B L H 4$ was clearly observed. The WBLH3 and WBLH4 transcript levels in transformed stamens of (cr)-CSdt7BS were similar to those in pistils.

Wknox 1 is an ortholog of the maize $k n 1$ homeobox gene functioning mainly in shoot, inflorescence and floral meristem [40,42]. WRS1 and WLG4 are wheat orthologs of maize rough sheath1 (rs1) and liguleless 4 (lg4) KNOX genes, respectively [43,44]. Maize $r s 1$ and lg4 belong to the class I KNOX gene family and play important roles in maintenance of shoot apical meristem (SAM) indeterminancy and differentiation of lateral organs [47-49]. Transcripts of Wknox1, WRS1 and WLG4 accumulated abundantly in SAM-containing

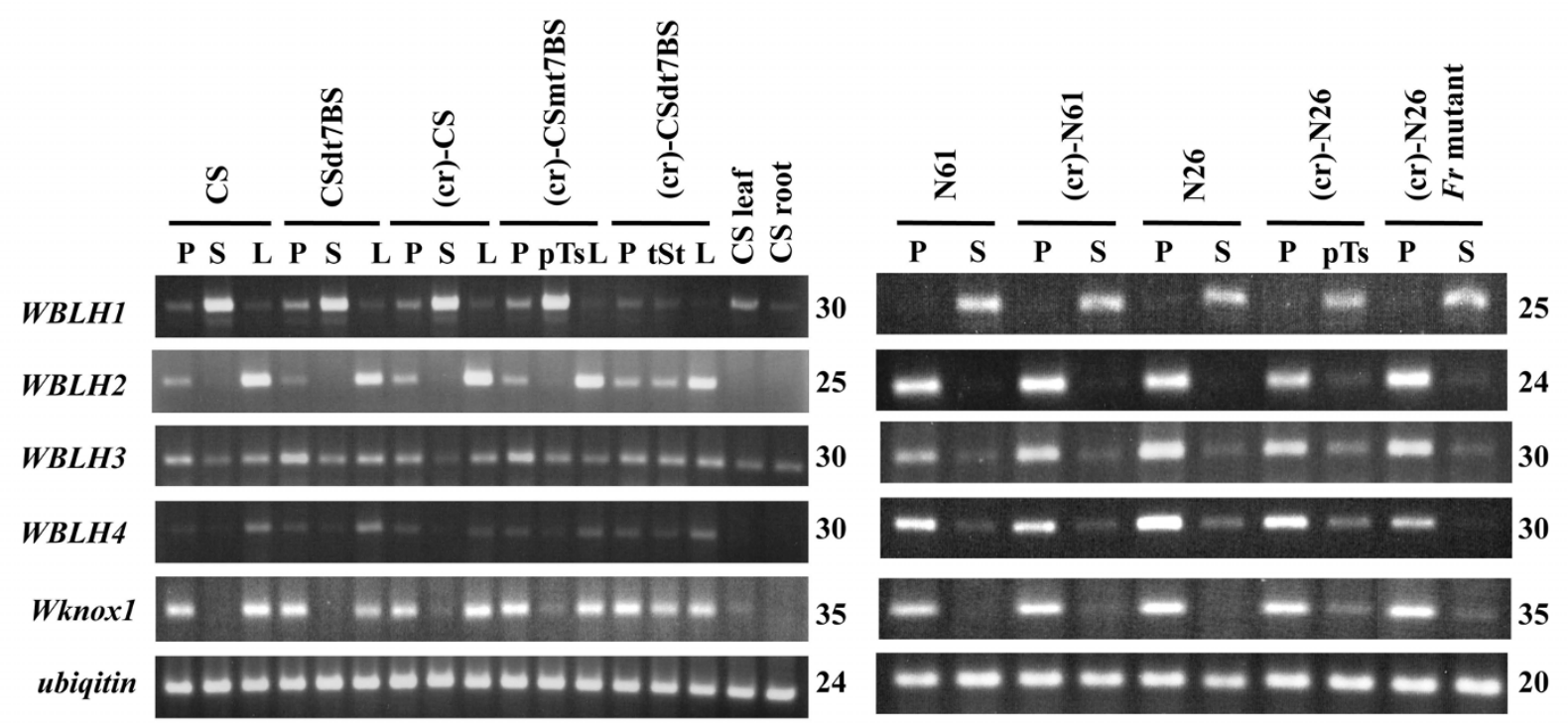

Figure 4 RT-PCR analysis of WBLH and Wknox 1 in various euplasmic and alloplasmic wheat lines. The Ubi gene was amplified as a control for normalization. Number of PCR cycles is shown on the right of each electropherogram. P, pistil; S, stamen; L, lodicule; PTs, partially transformed stamen; tSt, transformed stamen. 

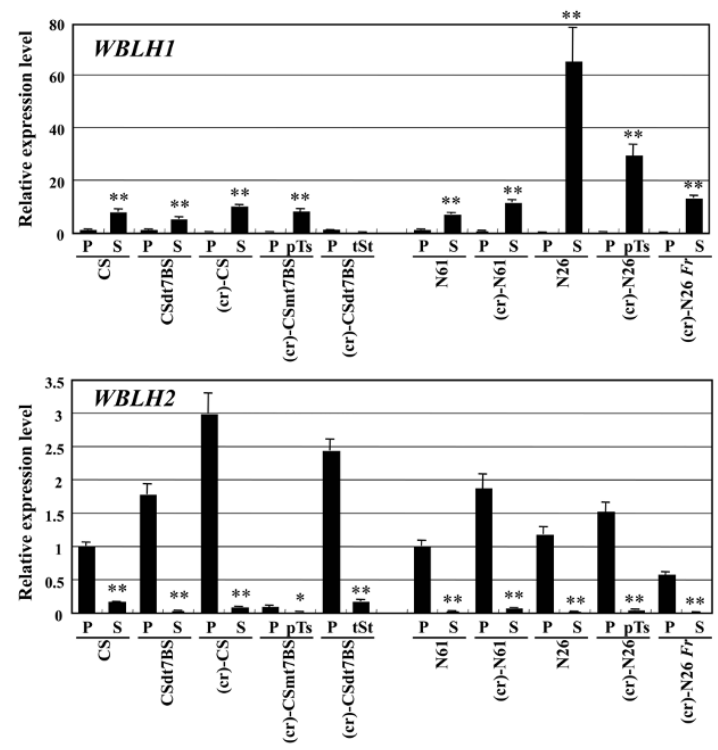

Figure 5 Quantitative RT-PCR analysis of WBLH1 and WBLH2 in euplasmic and alloplasmic lines of CS. Act was used as an internal control. The transcript levels are shown as values relative to the mRNA levels in pistils of CS. Data are represented as means with standard deviation ( $n=3$ or $n=4)$. One and two asterisks respectively indicate statistical significance between pistil and stamen at the $5 \%$ and $1 \%$ levels (Student's $t$ test). P, pistil; S, stamen; pTs, partially transformed stamen; tSt, transformed stamen.

embryos and young spikes and in floral organs, but not in fully developed leaf blades (Figure 3). Accumulation of Wknox 1 transcript was observed in pistils and lodicules of CS (Figure 4). Low levels of Wknox1 transcripts were detected in stamens of euplasmic and alloplasmic lines of CS, whereas slight Wknox 1 transcript accumulated in partially transformed stamens of (cr)-CSmt7BS. Wknox 1 transcripts accumulated abundantly in transformed stamens of (cr)-CSdt7BS, and the accumulation level was similar to that in pistils. Abundant expression of Wknox 1 in pistils was also observed in the other euplasmic and alloplasmic lines.

In situ localization of the four WBLH transcripts in pistils Fully developed ovules in normal pistils are surrounded by the inner and outer integuments, all enveloped by an inner epidermis (Figure 6A) [23]. To compare the expression patterns of the four $W B L H$ genes in pistil development of common wheat in detail, in situ hybridization analysis was conducted using pistils and young spikes at the floral organ developing stage, in which stamen and pistil primordia develop. In transverse sections of pistils from CS and CSdt7BS, accumulation of WBLH1 transcript was found in the ovary, but not the ovule (Figure 6B). In both pistils and transformed stamens of (cr)-CSdt7BS, WBLH1 transcripts were localized to the ovary but not the ovule. No significant differences in WBLH1 localization were observed among fertile pistils, sterile pistils, and transformed stamens. WBLH1 transcripts were also found in longitudinal sections of anthers, especially in tapetum and anther epidermis of CS (Figure 6C).

WBLH2 transcripts highly accumulated at the stage of floral organ development in the ovule of the CS, CSdt7BS and (cr)-CSdt7BS pistils (Figure 6D). WBLH2 mRNA was present at higher levels in the inner integument than in the outer integument and nucellus of the pistils. No significant difference in WBLH2 mRNA localization was observed between fertile and sterile pistils. Even in ectopic ovules of the transformed stamens, WBLH2 transcripts highly accumulated, although the integument developed incompletely.

In longitudinal sections of young spikes at the floral organ developing stage from CSdt7BS, WBLH3 mRNA was detected in the anther walls of the stamen and the basal region of the carpel but not in the ovule (Figure $6 \mathrm{E})$. WBLH3 transcripts accumulated in the central region of the transformed stamens of (cr)-CSdt7BS, where the ectopic ovule was presumed to develop. Similar expression patterns were observed for WBLH4 (data not shown).

\section{Protein-protein interaction between wheat BLH and KNOX}

Protein-protein interactions between BLH and KNOX were previously reported in Arabidopsis and barley $[31,34]$. The BLH-KNOX heterodimers play important roles in plant development $[30,32,33,50]$. To confirm the interactions between wheat BLH and KNOX proteins, a yeast two-hybrid assay was conducted. Entire ORF sequences of Wknox1, WRS1 and WLG4 were fused to the nucleotide sequence for the yeast GAL4 DNA binding domain (BD-WKNOX1, BD-WRS1 and BD-WLG4), and the WBLH1,WBLH2 and WBLH3 ORFs were fused to the sequence for the yeast GAL4 transcriptional activation domain (AD-WBLH1, AD-WBLH2 and $A D$ WBLH3). The yeast two-hybrid assay indicated that WBLH1 interacts with WKNOX1, WRS1 and WLG4 (Figure 7). WBLH3 also showed interaction with the three wheat KNOX proteins. WBLH2, however, formed a complex with WKNOX1 and WRS1, but not with WLG4.

To determine the KNOX-interacting domain of wheat BLH proteins, deletion-mutant constructs of WBLH1 and WBLH2 were produced, and protein-protein interaction of the WBLH1 and WBLH2 deletion proteins with WKNOX1 and WLG4 was examined by yeast twohybrid assay (Figure 8). NoWBLH1 deletion construct lacking the BEL domain showed positive interaction with WKNOX1 and WLG4 (Figure 8A). Neither 

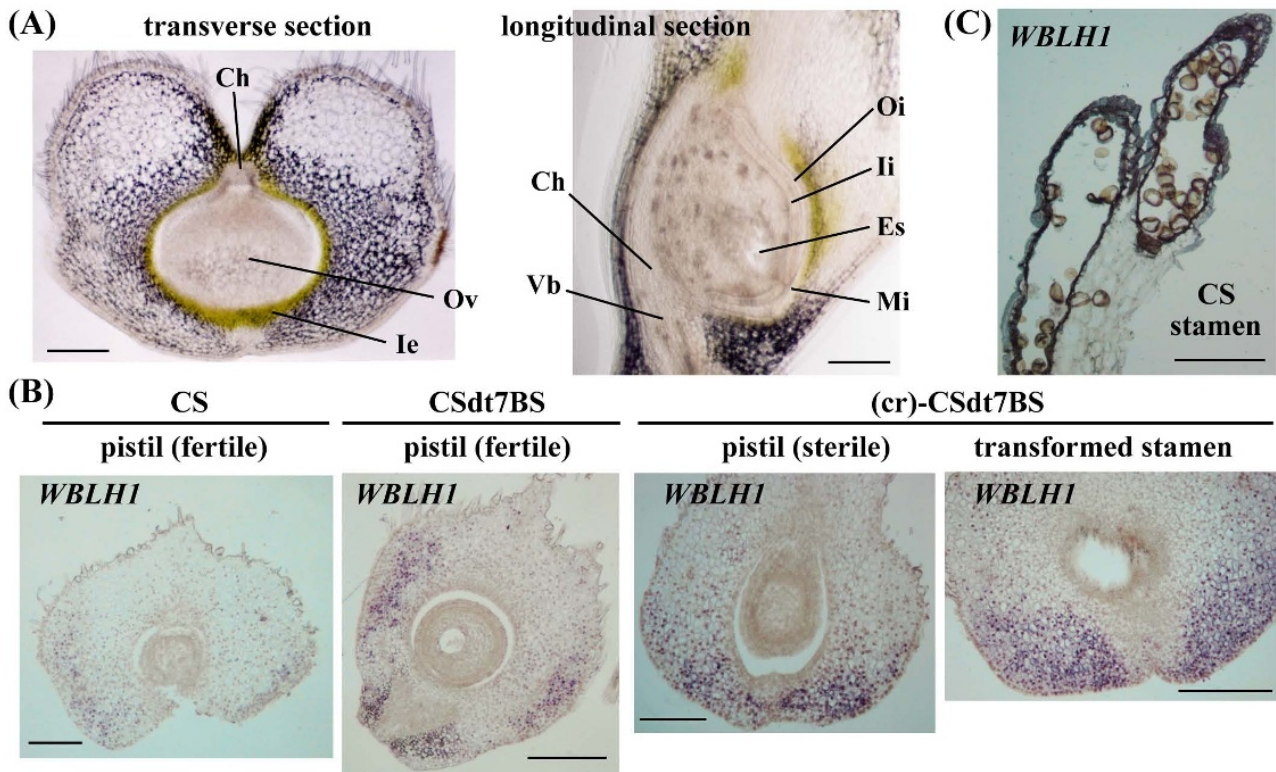

(cr)-CSdt7BS

(D)
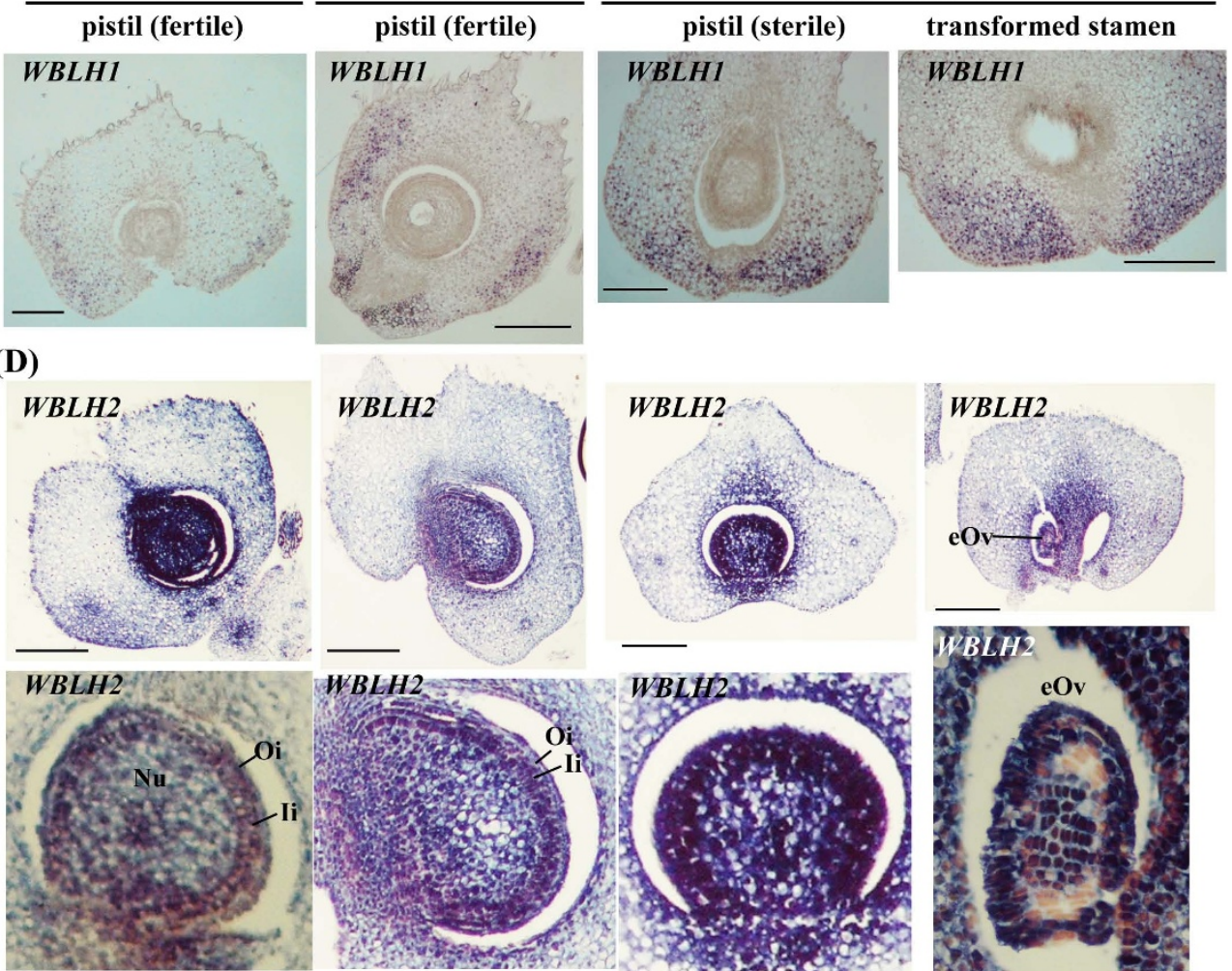

(E)

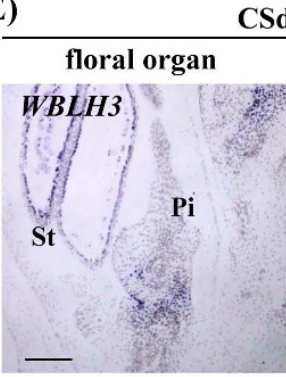

CSdt7BS
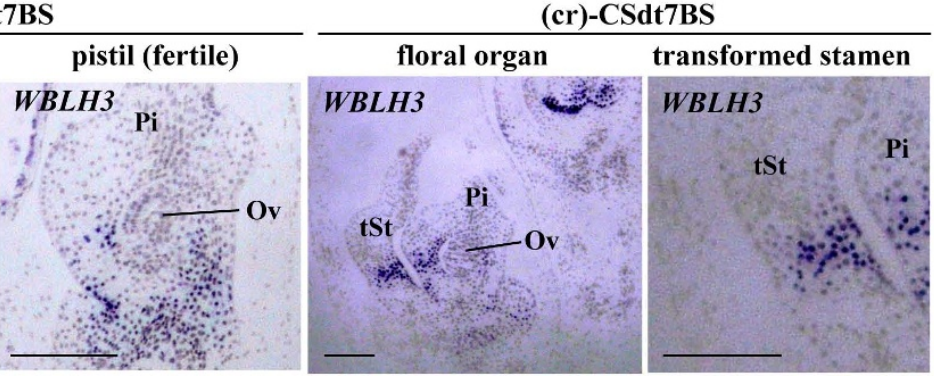

Figure 6 In situ hybridization of WBLH transcripts in floral organs of CS (wild-type), CSdt7BS (normal flower) and (cr)-CSdt7BS (flower showing pistillody). (A) Transverse (left) and longitudinal (right) sections of a normal, fully developed pistil from CSdt7BS. The ovule is enveloped by an inner epidermis. The vascular bundle is connected to the chalaza. (B) In situ localization of WBLH1 transcripts in transverse sections of pistils of euplasmic and alloplasmic CS lines. (C) In situ localization of WBLH1 transcripts in longitudinal sections of the CS stamens. (D) In situ localization of WBLH2 transcripts in transverse sections of pistils and stamens of euplasmic and alloplasmic CS lines. Lower panels show higher magnification images of the pistils. The magnified image of CS was derived from another section for in situ hybridization analysis of WBLH2 transcript. (E) In situ localization of WBLH3 transcripts in longitudinal sections of developing florets from euplasmic and alloplasmic lines of CSdt7BS. St, stamen; Pi, pistil; tSt, transformed stamen; Ov, ovule; le, inner epidermis; Ch, chalaza; Vb, vascular bundle; Es, embryo sac; Mi, micropyle; Oi, outer integument; li, inner integument; Nu, nucellus; eOv, ectopic ovule. Scale bars represent $100 \mu \mathrm{m}$. 
(A)

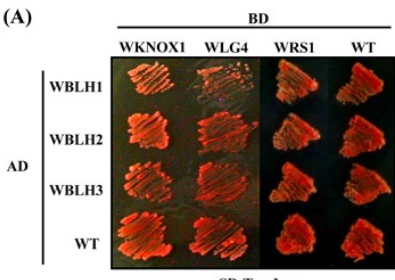

(B)

\begin{tabular}{|l|ccccc|}
\hline & BD-WKNOX1 & BD-WLG4 & BD-WRS1 & BD-WBLH1 & BD-WT \\
\hline AD-WBLH1 & $\circ$ & $\circ$ & $\bigcirc$ & N.D. & $\times$ \\
AD-WBLH2 & $\circ$ & $\times$ & $\bigcirc$ & N.D. & $\times$ \\
AD-WBLH3 & $\bigcirc$ & $\bigcirc$ & $\bigcirc$ & N.D. & $\times$ \\
AD-WT & $\times$ & $\times$ & $\times$ & 0 & $\circ$ \\
\hline
\end{tabular}

Figure 7 Interaction of WBLH and WKNOX proteins in a yeast two-hybrid system. (A) Transformed yeast lines were grown on SD medium without Trp and Leu (SD-Trp-Leu) (left) or SD medium lacking Trp, Leu and His (SD-Trp-Leu-His) (right). Protein interaction is assessed by the viability of yeast transformants on SD-Leu-Trp-His containing 3mM 3-AT. AD-WT and BD-WT, control plasmids.

(B) Summary of the results of the yeast two-hybrid assay. Circles and crosses respectively indicate interacting or activating, and noninteracting or nonactivating. N.D., not determined. Interaction of BD-WBLH1 and AD-WT is not shown.

deletion in the SKY domain nor the homeodomain of WBLH1 had any effect on protein-protein interactions with the two KNOX proteins. The N-terminal region of WBLH1 was also not required for the interactions. Arabidopsis BEL1 interacts with KNOX proteins through the N-terminal to homeodomain regions [34]. The interaction domain with KNOX was more restricted in WBLH1 than in BEL1. Similarly, deletions in the SKY and BEL domain region of WBLH2 abolished the interaction with WKNOX1, and a WBLH2 deletion without the homeodomain had no influence on the interaction (Figure 8B). Deletion analysis of WBLH2 indicated that the region from the SKY domain to the BEL domain was required for the interaction with WKNOX1. In addition, no deletion derivatives of WBLH2 showed positive interactions with WLG4, meaning the absence of any region inhibiting the interaction with WLG4 in WBLH2.

The entire ORF of WBLH1 was fused to the nucleotide sequence for the yeast GAL4 DNA binding domain. Yeast transformants carrying the BD-WBLH1 construct survived on $\mathrm{His}^{-}$selection medium, indicating that WBLH1 could activate transcription of the reporter gene used in yeast. To identify the activation-related domain, deletion derivatives of WBLH1 fused to the DNA binding domain were introduced, and transformants were recovered on $\mathrm{His}^{-}$selection medium. No WBLH1 constructs lacking either the SKY, BEL or homeodomains lost function as a transcriptional activator (Figure 8A). Deletion of the $\mathrm{N}$-terminal region failed to activate reporter gene expression. These results revealed that the $\mathrm{N}$-terminal region (119th to 349th amino acid residues) was essential for transcriptional activation.

\section{Discussion}

\section{WBLH2 function is distinct from those of other three $B L H$} genes

Bell1-type homeobox genes play important roles in plant development. In this study, four wheat $B L H$ genes were isolated and named WBLH1 to WBLH4. WBLH1, a putative ortholog of barley JuBEL1 [31], was highly similar to Arabidopsis SAWTOOTH1 (SAW1) and SAWTOOTH2 (SAW2), which act redundantly to suppress expression of the KNOX gene BREVIPEDICELLUS (BP) in leaf margins [30]. $S A W 1$ and $S A W 2$ expression was also observed in lateral organs including the adaxial side of developing sepals but not in developing ovules, and therefore $S A W 1$ and $S A W 2$ are unlikely to be redundant with $B E L 1$ function in ovule development, although the two genes are the most closely related in sequence to BEL1 [30]. WBLH1 was expressed in the ovary but not the ovule (Figure 6B), indicating that WBLH1 function also does not correspond to that of BEL1.

Both BEL1 and SAW1 are able to interact with class I KNOX proteins, STM, BP and KNAT2, and with the class II KNOX protein KNAT5, but not with other class II KNOX proteins, KNAT3, KNAT4 and KNAT7 $[30,35]$. The class I KNOX genes are considered to play a role in establishment and maintenance of meristematic identity and in the initiation of lateral organ primordia, and their expression patterns were temporally and spatially regulated, whereas expression of the class II KNOX genes is constitutive $[47,51,52]$. Similarly, WBLH1 could interact with three class I KNOX proteins, WKNOX1, WRS1 and WLG4 (Figure 7). Wknox1, WRS1 and WLG4 are related to KNAT1, BP and KNAT5, respectively $[36,40,43]$. Barley JuBEL1 also interacts with class I KNOX proteins BKN1 and BKN3, but not with class II KNOX protein BKN7 [31]. The interacting domain of WBLH1 could be defined to the BEL domain in this study (Figure 8), which was included in the interacting region of JuBEL1 [31]. These results imply evolutionary conservation of the protein-protein interaction between the class I KNOX proteins and WBLH1-related proteins since the divergence of monocotyledonous and dicotyledonous plants. In animals, interaction between two types of TALE-homeobox protein families plays important roles in development, and an $\mathrm{N}$-terminal portion of the PBX subclass proteins is essential for heterodimerization with the MEINOX subclass proteins $[53,54]$. The MEINOX-PBX complex in animals is evolutionarily conserved as the KNOX-BLH 
(A)

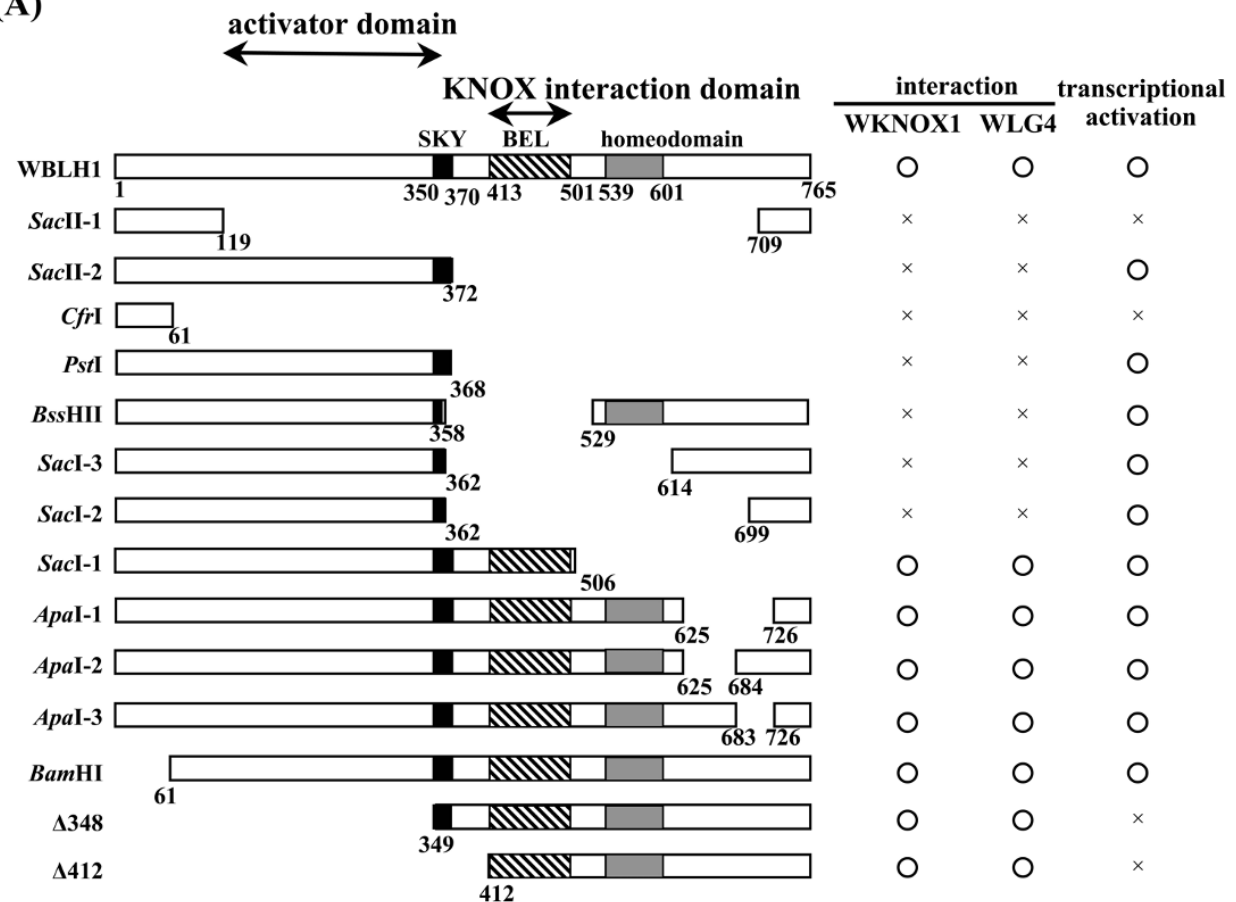

(B)
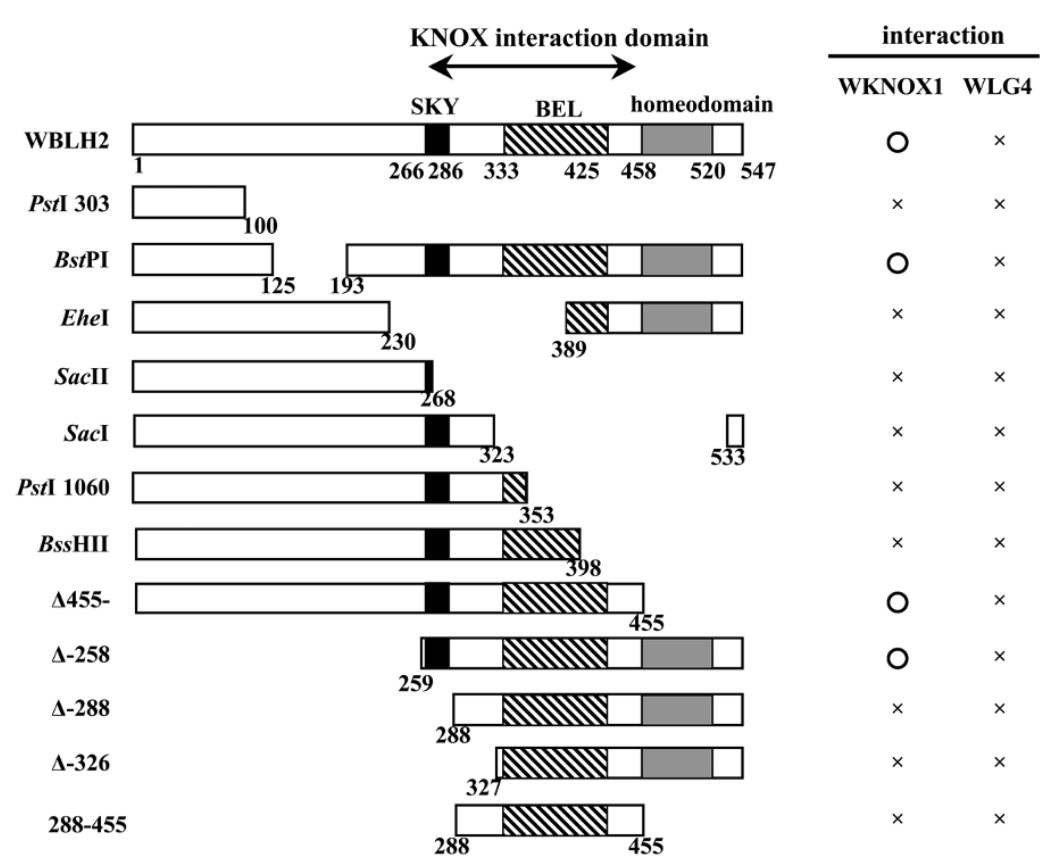

Figure 8 Structures of deletion derivatives of WBLH1 and WBLH2 and their interactions with wheat KNOX proteins. The SKY, BEL and homeobox domains are shown by yellow, green and red boxes, respectively. Numbers indicate amino acid residue numbers at the deletion break points. Interaction activity with WKNOX1 and WLG4 and transcriptional activity are also summarized on the right side. Circles indicate interacting or activating, and crosses indicate noninteracting or nonactivating. 
complex in plants [34]. KNOX-BLH interaction likely alters intracellular localization of the KNOX transcription factor [55], and the KN1-BLH complex binds to the specific DNA motif, TGACAG(G/C)T, with higher affinity compared with KN1 alone [56]. These observations surely indicate the significance of KNOX-BLH complex formation in various plant developmental processes.

WBLH3 also interacted with the three class I KNOX proteins (Figure 7). WBLH3 was phylogenetically close to $W B L H 4$, a putative ortholog of barley JuBEL2 [31,57], although the chromosomal locations of WBLH3 and WBLH4 were different. RT-PCR and in situ mRNA hybridization analyses revealed that the gene expression profile of $W B L H 3$ was generally identical to that of WBLH4. WBLH3 and WBLH4 were homologous to Arabidopsis BLH1 (Figure 2B). WBLH3 and WBLH4 expression was observed in the basal region of the carpel but not the ovule (Figure 6E). Similarly, Arabidopsis BLH1 expression is restricted to the transmitting tract and the base of the funiculus, but is not observed in the ovule or embryo sac [58]. Therefore, the WBLH3/4 expression patterns were well conserved with that of $B L H 1$. Misexpression of $B L H 1$ affects normal embryo sac development in ovules of the Arabidopsis eostre mutant [58]. A mutation of the class II KNOX gene KNAT3 suppresses the eostre mutant phenotype [58], and KNAT3 is able to interact with BLH1 [58]. Hackbusch et al. [59] and Pagnussat et al. [58] also reported that the function of the Arabidopsis KNOX-BLH complexes requires the ovate family proteins. No misexpression of $W B L H 3 / 4$ was observed in ovules of the euplasmic and alloplasmic wheat lines, and therefore we have no information about functional orthology between $B L H 1$ and WBLH3/ 4. WBLH3 displays similarity to the rice qSH1 homeobox protein, a putative ortholog of the Arabidopsis REPLUMLESS (RPL) homeobox protein [29,60]. RPL and $q S H 1$ are associated with seed shattering. RPL is expressed in Arabidopsis stem, pedicels and replum of developing ovaries, and $q S H 1$ is expressed in rice inflorescence meristem, anther and the boundary of the spikelets. WBLH3 might function to define the boundary regions as do $R P L$ and $q S H 1$.

WBLH2, closely related to the Arabidopsis ATH1 homeobox gene, was phylogenetically distinct from other wheat $B L H$ genes (Figure $2 \mathrm{~B}$ ). ATH1 was originally isolated as a light-induced homeobox gene [46]. ATH1 is expressed in shoot, inflorescence and floral meristems, developing stamens and carpels, and basal regions of lateral organs including leaves, sepals and petals [61]. The mutant phenotype of ath1 indicates that ATH1 controls the development of the boundary region between shoot lateral organs and the stem [61]. The ATH1-STM complex is associated with initiation and maintenance of Arabidopsis SAM [50]. AHT1 expression in stamens and carpels is consistent with the activation of ATH1 by AGAMOUS [62]. In contrast to the ATH1 expression pattern, WBLH2 was abundantly expressed in ovules but not in ligule or auricle regions (Figure 3, Figure 6D). The WBLH2 expression pattern is likely to be analogous to that of BEL1 rather than ATH1. Especially in integuments of ovules, WBLH2 transcripts accumulated abundantly, indicating that WBLH2 might be associated with development of integuments in wheat. The ovule-specific expression of WBLH2 clearly differed from the expression patterns of three other wheat $B L H$ genes. In addition, of the class I KNOX proteins examined, WBLH2 was not able to interact with WLG4 (Figure 7). The interacting region of WBLH2 with WKNOX1 was defined from the SKY domain to the BEL domain, which was broader than the interacting region of WBLH1 with WKNOX1 and WLG4 (Figure 8). These observations reveal that the functional features of WBLH2 are distinct from those of the other $B L H$ gene functions in wheat development. In particular, the role of WBLH2 in ovule development should be elucidated in further studies.

\section{Altered expression of BEL1-type homeobox genes in floral organs of alloplasmic lines}

Pistillody is one of the typical phenomena appearing in nuclear-cytoplasm incompatibility of higher plants. For expression of pistillody, the expression patterns of a large number of nuclear genes including class B MADSbox genes are altered $[6,63]$. The downregulation of the class B MADS-box genes in stamen primordia results in homeotic conversion at floral whorl three in the pistillody-showing alloplasmic lines as well as loss-of-function mutants of the class B MADS-box genes. Within their pistil-like stamens, ectopic ovules are surely formed as reported in Arabidopsis, rice and alloplasmic wheat $[6,64,65]$. Our previous studies revealed that wheat class B MADS-box genes WPI1, WPI2 and WAP3 are downregulated at floral whorl three in alloplasmic wheat lines showing pistillody $[6,14]$, whereas two class C MADSbox genes, WAG-1 and WAG-2, and TaDL, an ortholog of rice DROOPING LEAF $(D L)$, are ectopically expressed in primordia of the pistil-like transformed stamens $[15,16,23,66]$. After floral organ identity is homeotically changed at whorl three, ovule formation is likely to automatically occur within the transformed stamens through expression of the class D MADS-box gene TaAGL2/WSTK [23]. During ectopic ovule development, expression of WBsis and WANT-1 is observed in integuments of the ovules $[16,23]$. WBLH2 was also strongly expressed in integuments not only of normal ovules in pistils but also of ectopic ovules in transformed stamens (Figure 6). WBLH1/WBLH3/WBLH4 expression was observed in the basal boundary region of the ovary in 
both normal pistils and transformed stamens. These observations suggest that expression of the four WBLH genes is associated with development of transformed stamens in alloplasmic wheat lines with Ae. crassa cytoplasm.

Ectopic ovules in transformed stamens and ovules in pistils of (cr)-CSdt7BS are sterile due to abnormal development of the inner epidermis and integuments [6,23]. It was thought that aberrant expression of WBsis and a reduced transcript level of WANT-1 might at least partially result in the sterility of the ovules and ectopic ovules [16,23] (Murai et al. unpublished results). Such an obvious alteration of gene expression in the ovules and ectopic ovules was not observed in WBLH2. The WBLH2 expression pattern in the sterile pistils seemed to be identical to that in normal ovules of fertile pistils (Figure 6D). Therefore, we have no evidence for WBLH2 being associated with the female sterility of the transformed stamens and pistils in (cr)-CSdt7BS. The regulatory pathway of WBLH2 expression in ovule development might be independent of those of WBsis and WANT-1. After WAG-1 and WAG-2 expression in the transformed stamens and sterile pistils, WSTK initiates ovule development [23]. WBLH2 expression occurs continuously in the developing ovules of the transformed stamens and sterile pistils, whereas WBsis is ectopically expressed in the marginal region of ovule primordia and WANT-1 expression level is reduced around ovule primordia [16,23] (Murai et al. unpublished results). After ovule initiation via WSTK, some of the ovule development-related genes such as WBsis and WANT-1 should be abnormally expressed, which in turn might be associated with the aberrant ovule development. In further studies, signal cascades from initiation of ovule primordia to WBsis/WANT-1 or WBLH2 expression should be elucidated to investigate how the Ae. crassa cytoplasm and $R f d 1$ affect female sterility in the pistillody-exhibiting alloplasmic wheat lines.

\section{Conclusions}

Wheat $B L H$ genes consist of a small multigene family. Four wheat Bell1-like homeobox $(B L H)$ genes, WBLH1 to $W B L H 4$, were isolated in this study. A yeast twohybrid assay showed that KNOX-BLH interaction was conserved in wheat similarly to in various other plant species, indicating the significance of KNOX-BLH complex formation in wheat developments. Of the class I KNOX proteins examined, WBLH2 was unable to interact with WLG4. The interacting region of WBLH2 with WKNOX1 was defined from the SKY domain to the BEL domain, which was broader than the interacting region of WBLH1 with WKNOX1 and WLG4. In addition, the ovule-specific expression of WBLH2 clearly differed from the expression patterns of three other wheat
$B L H$ genes. Therefore, the functional features of WBLH2 are likely to be distinct from other $B L H$ gene functions in wheat development. WBLH2 was also strongly expressed in integuments not only of normal ovules in pistils but also of ectopic ovules in transformed stamens. WBLH1/WBLH3/WBLH4 expression was observed in the basal boundary region of the ovary in both normal pistils and transformed stamens. These results indicated that the four $W B L H$ genes may participate in development of pistils and transformed stamens but are not associated with female sterility in alloplasmic wheat lines with Ae. crassa cytoplasm.

\section{Additional material}

Additional file 1: Comparison of nucleotide sequences of 63 RT-PCR products with BLH-degenerate primers.

Additional file 2: Amino acid sequence alignment of three conserved domains in the WBLH proteins.

Additional file 3: Copy number and chromosome assignment of the four WBLH genes.

\section{Acknowledgements}

We thank Dr. S. Cloutier for providing the EST clone TaLr1107F03R. Wheat seeds used in this study were supplied by the National BioResource ProjectWheat (Japan; http://www.nbrp.jp). This work was supported by a grant from the Ministry of Education, Culture, Sports, Science and Technology of Japan (Basic Research B, No. 21380005) to ST, and partially supported by Special Coordination Funds for Promoting Science and Technology, Creation of Innovation Centers for Advanced Interdisciplinary Research Areas (Innovative Bioproduction Kobe), MEXT, Japan.

\section{Author details}

${ }^{1}$ Graduate School of Agricultural Science, Kobe University, Nada-ku, Kobe 657-8501, Japan. ²Department of Bioscience, Fukui Prefectural University, Yoshida-gun, Fukui 910-1195, Japan.

\section{Authors' contributions}

KMi designed the experiments, carried out the molecular genetic studies, and drafted the manuscript. HH participated in the real-time RT-PCR analysis. $\mathrm{CH}$ carried out the in situ hybridization. KMu participated in the design and coordination of the study and helped to draft the manuscript. ST conceived of the study, designed and coordinated the study, and wrote the manuscript. All authors read and approved the final manuscript.

Received: 7 September 2010 Accepted: 4 January 2011 Published: 4 January 2011

\section{References}

1. Kaul MLH: Male sterility in higher plants Berlin: Springer; 1988.

2. Tsunewaki K: Genome-plasmon interactions in wheat. Jpn J Genet 1993, 68:1-34

3. Tsunewaki K, Wang GH, Matsuoka Y: Plasmon analysis of Triticum (wheat) and Aegilops. 1. Production of alloplasmic common wheats and their fertilities. Genes Genet Syst 1996, 71:293-311.

4. Schnable PS, Wise RP: The molecular basis of cytoplasmic male sterility and fertility restoration. Trends Plant Sci 1998, 3:175-180.

5. Zubko MK, Zubko El, Patkovsky YV, Khvedynich OA, Fisahn J, Gleba YY, Schieder O: Novel 'homeotic' CMS patterns generated in Nicotiana via cybridization with Hyoscyamus and Scopolia. J Exp Bot 1996, 47:1101-1110.

6. Murai K, Takumi S, Koga H, Ogihara Y: Pistillody, homeotic transformation of stamens into pistil-like structures, caused by nuclear-cytoplasm interaction in wheat. Plant J 2002, 29:169-181. 
7. Linke B, Nothnagel T, Böner T: Flower development in carrot CMS plants: mitochondria affect the expression of MADS box genes homologous to GLOBOSA and DEFICIENS. Plant I 2003, 34:27-37.

8. Teixeira RT, Farbos I, Glimelius K: Expression levels of meristem identity and homeotic genes are modified by nuclear-mitochondrial interactions in alloplasmic male-sterile lines of Brassica napus. Plant J 2005, 42:731-742.

9. Fitter JT, Thomas MR, Niu C, Rose RJ: Investigation of Nicotiana tabacum (+) N. suaveolens cybrids with carpelloid stamens. J Plant Physiol 2005, 162:225-235.

10. Murai K, Tsunewaki K: Photoperiod-sensitive cytoplasmic male sterility in wheat with Aegilops crassa cytoplasm. Euphytica 1993, 67:41-48.

11. Murai K: Genetic analysis of fertility restoration against photoperiodsensitive cytoplasmic male sterility in Triticum aestivum cv. Norin 61. Plant Breed 1997, 116:592-594.

12. Zhu Y, Saraike T, Yamamoto Y, Hagita H, Takumi S, Murai K: orf260 cra a novel mitochondrial gene, is associated with the homeotic transformation of stamens into pistil-like structures (pistillody) in alloplasmic wheat. Plant Cell Physiol 2008, 49:1723-1733.

13. Murai K, Tsunewaki K: Genetic analysis on the fertility restoration by Triticum aestivum cv. Chinese Spring against photoperiod-sensitive cytoplasmic male sterility. Jpn J Genet 1994, 69:195-202.

14. Hama E, Takumi $\mathrm{S}$, Ogihara $\mathrm{Y}$, Murai $\mathrm{K}$ : Pistillody is caused by alterations to the class-B MADS-box gene expression pattern in alloplasmic wheats. Planta 2004, 218:712-720

15. Meguro A, Takumi S, Ogihara Y, Murai K: WAG, a wheat AGAMOUS homolog, is associated with development of pistil-like stamens in alloplasmic wheats. Sex Plant Reprod 2003, 15:221-230

16. Mizumoto K, Hatano H, Hirabayashi C, Murai K, Takumi S: Altered expression of wheat AINTEGUMENTA homolog, WANT-1, in pistil and pistil-like transformed stamen of an alloplasmic line with Aegilops crassa cytoplasm. Dev Genes Evol 2009, 219:175-187.

17. Riechmann JL, Meyerowitz EM: MADS domain proteins in plant development. Biol Chem 1997, 378:1079-1101.

18. Angenent GC, Franken J, Busscher M, van Dijken A, van Went JL, Dons HJM, van Tunen AJ: A novel class of MADS box genes is involved in ovule development. Plant Cell 1995, 7:1569-1582.

19. Colombo L, Franken J, Koetje E, van Went J, Dons HJM, Angenent GC, van Tunen AJ: The Petunia MADS box gene FBP11 determines ovule identity. Plant Cell 1995, 7:1859-1868.

20. Favaro R, Pinyopich A, Battaglia R, Kooiker M, Borghi L, Ditta G, Yanofsky MF, Kater MM, Colombo L: MADS-box protein complexes control carpel and ovule development in Arabidopsis. Plant Cell 2003, 15:2603-2611.

21. Nesi N, Debeauion I, Jond C, Stewart AJ, Jenkins GI, Caboche M, Lepiniec L. The TRANSPARENT TESTA 16 locus encodes the ARABIDOPSIS BSISTER MADS domain protein and is required for proper development and pigmentation of the seed coat. Plant Cell 2002, 14:2463-2479.

22. de Folter S, Shchennikova AV, Franken J, Busscher M, Baskar R, Grossniklaus U, Angenent GC, Immink RGH: A $B_{\text {sister }}$ MADS-box gene involved in ovule and seed development in petunia and Arabidopsis. Plant J 2006, 47:934-946.

23. Yamada K, Saraike T, Shitsukawa N, Takumi S, Murai K: Class D and $B_{\text {sister }}$ MADS-box genes are associated with the ectopic ovule formation in the pistil-like stamens of alloplasmic wheat (Triticum aestivum L.). Plant Mol Biol 2009, 71:1-14.

24. Schneitz $\mathrm{K}$ : The molecular and genetic control of ovule development. Curr Opi Plant Biol 1999, 2:13-17.

25. Baker SC, Robinson-Beers K, Villanueva JM, Gaiser JC, Gasser CS: Interactions among genes regulating ovule development in Arabidopsis thaliana. Genetics 1997, 145:1109-1124.

26. Schneitz K, Hülskamp M, Kopczak SD, Pruitt RE: Dissection of sexual organ ontogenesis: a genetic analysis of ovule development. Development 1997 124:1367-1376.27.

27. Reiser L, Modrusan Z, Margossian L, Samach A, Ohad N, Haughn GW, Fishcher RL: The BELL1 gene encodes a homeodomain protein involved in pattern formation in the Arabidopsis ovule primordium. Cell 1995, 83:735-742.

28. Western T, Haughn G: BELL1 and AGAMOUS genes promote ovule identity in Arabidopsis thaliana. Plant J 1999, 18:329-336.
29. Konishi S, Izawa T, Lin SY, Ebana K, Fukuta Y, Sasaki T, Yano M: An SNP caused loss of seed shattering during rice domestication. Science 2006, 312:1392-1396.

30. Kumar R, Kushakappa K, Godt D, Oidkowich MS, Pastorelli S, Hepworth SR, Haughn GW: The Arabidopsis BEL1-LIKE HOMEODOMAIN protein SAW1 and SAW2 act redundantly to regulate KNOX expression spatially in leaf margins. Plant Cell 2007, 19:2719-2735.

31. Müller J, Wang Y, Franzen R, Santi L, Salamini F, Rohde W: In vitro interactions between barley TALE homeodomain proteins suggest a role for protein-protein associations in the regulation of Knox gene function. Plant J 2001, 27:13-23.

32. Bryne ME, Groover AT, Fontana JR, Martienssen RA: Phyllotactic pattern and stem cell fate are determined by the Arabidopsis homeobox gene BELLRINGER. Development 2003, 130:3941-3950.

33. Smith HM, Hake $S$ : The interaction of two homeobox genes, BREVIPEDICELLUS and PENNYWISE, regulates internode patterning in the Arabidopsis inflorescence. Plant Cell 2003, 15:1717-1727.

34. Bellaoui M, Pidkowich MS, Samach A, Kushalappa K, Kohalmi SE, Modrusan Z, Crosby WL, Haughn GW: The Arabidopsis BELL1 and KNOX TALE homeodomain proteins interact through a domain conserved between plants and animals. Plant Cell 2001, 13:2455-2470.

35. Mukherjee $K$, Brocchieri L, Bürglin TR: A comprehensive classification and evolutionary analysis of plant homeobox genes. Mol Biol Evol 2009, 26:2775-2794.

36. Murai K, Ogihara Y, Tsunewaki K: An EMS-induced wheat mutant restoring fertility against photoperiod-sensitive cytoplasmic male sterility. Plant Breed 1995, 114:205-209.

37. Sears ER: Nullisomic-tetrasomic combinations in hexaploid wheat. In Chromosome manipulation and plant genetics. Edited by: Riley R, Lewis KR. Edinburgh: Oliver and Boyd; 1966:29-45.

38. Karlin S, Altschul SF: Applications and statistics for multiple high-scoring segments in molecular sequences. Proc Natl Acad Sci USA 1993, 90:5873-5877.

39. Sneath PHA, Sokal RR: Numerical Taxonomy Freeman: San Francisco; 1973.

40. Takumi S, Kosugi T, Murai K, Mori N, Nakamura C: Molecular cloning of three homoeologous CDNAs encoding orthologues of maize KNOTTED homeobox protein from young spikes of hexaploid wheat. Gene 2000 249:171-181.

41. Mizumoto K, Murai K, Nakamura C, Takumi S: Preferential expression of a HLP homolog encoding a mitochondrial L14 ribosomal protein in stamens of common wheat. Gene 2004, 343:281-289.

42. Morimoto R, Kosugi T, Nakamura C, Takumi S: Intragenic diversity and functional conservation of the three homoeologous loci of the KN1-type homeobox gene Wknox1 in common wheat. Plant Mol Biol 2005, 57:907-924.

43. Morimoto R, Nishioka E, Murai K, Takumi S: Functional conservation of wheat orthologs of maize rough sheath1 and rough sheath2 genes. Plant Mol Biol 2009, 69:273-285.

44. Ishida Y, Takumi S: Cloning of a wheat CDNA encoding an ortholog of the maize LIGULELESS4 homeobox protein. Wheat Inf Serv 2009, 107:9-12.

45. Saraike T, Shitsukawa N, Yamamoto Y, Hagita H, Iwasaki Y, Takumi S, Murai K: Identification of a protein kinase gene associated with pistillody, homeotic transformation of stamens into pistil-like structures, in alloplasmic wheat. Planta 2007, 227:211-221.

46. Quaedvlieg N, Dockx J, Rook F, Weisbeek P, Smeekens S: The homeobox gene $A T H 1$ of Arabidopsis is depressed in the photomorphogenic mutants cop1 and det1. Plant Cell 1995, 7:117-129.

47. Kerstetter RA, Vollbrecht E, Lowe B, Veit B, Yamaguchi J, Hake S: Sequence analysis and expression patterns divide the maize knotted1-like homeobox genes into two classes. Plant Cell 1994, 6:1877-1887.

48. Kerstetter RA, Laudencia-Chigcuanco D, Smith LG, Hake S: Loss-of-function mutations in the homeobox gene, knotted1, are defective in shoot meristem maintenance. Development 1997, 124:3045-3054.

49. Bauer P, Lubkowitz M, Tyers R, Nemoto K, Meeley RB, Goff SA, Freeling M: Regulation and a conserved intron sequence of liguleless $3 / 4$ knox class-I homeobox genes in grasses. Planta 2004, 219:359-368.

50. Rutjens B, Bao D, van Eck-Stouten E, Brand M, Smeekens S, Proveniers M: Shoot apical meristem function in Arabidopsis requires the combined activities of three BEL1-like homeodomain proteins. Plant J 2009, 58:641-654. 
51. Jackson D, Veit B, Hake S: Expression of maize KNOTTED1 related homeobox genes in the shoot apical meristem predicts patterns of morphogenesis in the vegetative shoot. Development 1994, 120:405-413.

52. Sentoku N, Sato Y, Kurata N, Ito Y, Kitano H, Matsuoka M: Regional expression of the rice KN1-type homeobox gene family during embryo, shoot, and flower development. Plant Cell 1999, 11:1651-1663.

53. Bürglin TR: The PBC domain contains a MEINOX domain: Coevolution of Hox and TALE homeobox genes? Dev Genes Evol 1998, 208:113-116.

54. Mann RS, Affolter M: Hox proteins meet more partners. Curr Opin Genet Dev 1998, 8:423-429.

55. Cole M, Nolte C, Werr W: Nuclear import of the transcription factor SHOOT MERISTEMLESS depends on heterodimerization with BLH proteins expressed in discrete sub-domains of the shoot apical meristem of Arabidopsis thaliana. Nucleic Acid Res 2006, 34:1281-1292.

56. Smith HM, Boschke I, Hake S: Selective interaction of plant homeodomain proteins mediates high DNA-binding affinity. Proc Natl Acad Sci USA 2002, 99:9579-9584.

57. Dabbert T, Okagaki RJ, Cho S, Heinen S, Boddu J, Muehlbauer GJ: The genetics of barley low-tillering mutants: low number of tillers-1 (Int1). Theor Appl Genet 2010, 121:705-715.

58. Pagnussat GC, Yu HJ, Sundaresan V: Cell-fate switch of synergid to egg cell in Arabidopsis eostre mutant embryo sacs arises from misexpression of the BEL1-like homeodomain gene BLH1. Plant Cell 2007, 19:3578-3592.

59. Hackbusch J, Richter K, Müller J, Salamini F, Uhrig JF: A central role of Arabidopsis thaliana ovate family proteins in networking and subcellular localization of 3-aa loop extension homeodomain proteins. Proc Natl Acad Sci USA 2005, 102:4908-4912.

60. Roeder AHK, Ferrándiz C, Yanofsky MF: The role of the REPLUMLESS homeodomain protein in patterning the Arabidopsis fruit. Curr Biol 2003, 13:1630-1635.

61. Gómez-Mena C, Sablowski R: ARABIDOPSIS THALIANA HOMEOBOX GENE1 establishes the basal boundaries of shoot organs and controls stem growth. Plant Cell 2008, 20:2059-2072.

62. Gómez-Mena C, de Folter S, Costa MMR, Angenent GC, Sablowski R: Transcriptional program controlled by the floral homeotic gene AGAMOUS during early organogenesis. Development 2005, 132:429-438.

63. Carlsson J, Lagercrantz U, Sundström J, Teizeira R, Wellmer F, Meyerowitz EM, Gilmelius K: Microarray analysis reveals altered expression of a large number of nuclear genes in developing cytoplasmic male sterile Brassica napus flower. Plant J 2007, 49:452-462.

64. Hill JP, Lord EM: Floral development in Arabidopsis thaliana: a comparison of the wild type and the homeotic pistillata mutant. Can $J$ Bot 1989, 67:2922-2936.

65. Nagasawa N, Miyoshi M, Sano Y, Satoh H, Hirano H, Sakai H, Nagato Y: SUPERWOMAN1 and DROOPING LEAF genes control floral organ identity in rice. Development 2003, 130:705-718.

66. Ishikawa M, Ohmori Y, Tanaka W, Hirabayashi C, Murai K, Ogihara Y, Yamaguchi T, Hirano H: The spatial expression patterns of DROOPING LEAF orthologs suggest a conserved function in grasses. Gene Genet Syst 2009, 84:137-146.

doi:10.1186/1471-2229-11-2

Cite this article as: Mizumoto et al:: Characterization of wheat Bell1-type homeobox genes in floral organs of alloplasmic lines with Aegilops crassa cytoplasm. BMC Plant Biology 2011 11:2.

\section{Submit your next manuscript to BioMed Central and take full advantage of:}

- Convenient online submission

- Thorough peer review

- No space constraints or color figure charges

- Immediate publication on acceptance

- Inclusion in PubMed, CAS, Scopus and Google Scholar

- Research which is freely available for redistribution

Submit your manuscript at www.biomedcentral.com/submit
Biomed Central 